\title{
ÁCIDO LINOLEICO CONJUGADO: ESTRUTURA QUÍMICA, EFEITOS SOBRE A SAÚDE HUMANA E ANÁLISE EM LÁCTEOS
}

\section{Conjugated linoleic acid: chemical structure, occurrence and effects on human health}

Juliana Nunes Lucattol, Saraspathy N. T. G. de Mendonça ${ }^{l}$, Deisy Alessandra Drunkler ${ }^{* *}$

\section{RESUMO}

Denomina-se ácido linoleico conjugado (CLA) o grupo de isômeros posicionais e geométricos do ácido linoleico, que por serem naturalmente sintetizados no rúmen de animais, têm como principal fonte os alimentos derivados do leite e as carnes provenientes dos ruminantes. Há mais de duas décadas, inúmeros estudos tanto em animais quanto em humanos vêm relacionando o CLA a efeitos benéficos diversos tais como redução da carcinogênese, da aterosclerose, da massa lipídica corporal, aumento da massa muscular, entre outros. O presente trabalho teve como objetivo apresentar um panorama dos estudos relacionados ao CLA, no que diz respeito à síntese em animais e por bactérias láticas, bem como os efeitos benéficos cientificamente comprovados e formas de quantificação, sempre enfatizando leite e derivados lácteos.

Palavras-chave: ácido graxo; isômeros; leite; CLA.

\begin{abstract}
Conjugated linoleic acid (CLA) is the group of positional and geometric isomers of linoleic acid, which are naturally synthesized in the rumen of animals. The main dietary sources of CLA are milk, dairy products end meat from ruminant animals. For over two decades, numerous studies both in animals and in humans, have been linking CLA to several beneficial effects such as reduction of carcinogenesis, atherosclerosis,
\end{abstract}

1 Universidade Tecnológica Federal do Paraná (UTFPR), Programa de Pós-Graduação em Tecnologia de Alimentos (PPGTA), nível Mestrado Acadêmico, Av. Brasil, 4232, Parque Independência, 85884-000, Medianeira, PR, Brasil. E-mail: deisydrunkler@utfpr.edu.br

* Autor para correspondência. 
body fat mass and increase muscle mass. This study aimed to present an overview of current studies related to CLA, regarding the synthesis of CLA by lactic acid bacteria and in animals rumen, as well as the beneficial effects and scientifically proved ways to quantify, always emphasizing milk and milk products.

Keywords: fatty acid; isomers; milk, CLA.

\section{INTRODUÇÃO}

Os ácidos graxos são classificados em saturados, quando da ausência de insaturações em sua cadeia, monoinsaturados e poli-insaturados, de acordo com o número de insaturações. A maior parte dos ácidos graxos insaturados presentes nos alimentos apresenta conformação cis (hidrogênios posicionados no mesmo lado da dupla ligação), mas determinados processos químicos podem isomerizar as insaturações à configuração trans, invertendo os hidrogênios ligados à dupla ligação e provocando a linearização da cadeia (MARTIN et al., 2007; LEDOUX et al., 2007). A hidrogenação parcial de óleos vegetais na indústria é a principal fonte de ácidos graxos trans (AGT). Esses compostos, entretanto, também são formados em pequena quantidade durante a biohidrogenação bacteriana dos ácidos graxos insaturados no rúmen de animais poligástricos tais como bovinos, ovinos e caprinos, o que faz com que sejam encontrados principalmente no leite e na carne de animais ruminantes (MOTARDBÉLANGER et al., 2008).

O consumo de ácidos graxos trans tem sido frequentemente associado a um maior risco de desenvolvimento de doenças cardiovasculares (MOZAFFARIAN et al., 2006); no entanto, isômeros conjugados do ácido linoleico, denominados de ácido linoleico conjugado (em inglês conjugated linoleic acid - CLA), têm despertado um interesse especial por parte dos pesquisadores devido propriedades benéficas (KOBA; YANAGITA, 2013).

Assim, pesquisas com o CLA em leite e derivados têm aumentado significativamente nos últimos anos, tanto no que diz respeito à procura por matérias-primas com maior conteúdo deste ácido graxo até procedimentos capazes de aumentar a concentração de CLA em leite e derivados. Como consequência, metodologias para extração e quantificação de CLA também vem sendo pesquisadas.

Esta revisão tem como objetivo apresentar um panorama dos estudos relacionados ao CLA, no que diz respeito à estrutura química, síntese em animais e por bactérias, presença em leite e derivados lácteos e fatores benéficos associados ao consumo deste ácido graxo, assim como métodos para extração e quantificação de CLA em leite e derivados lácteos.

\section{REFERENCIAL TEÓRICO}

\section{Estrutura química do ácido linoleico con- jugado}

O termo CLA refere-se à mistura dos isômeros posicionais e geométricos do ácido linoleico (AL) (ANDRADE et al., 2012). Os 27 isômeros do CLA já relatados são apresentados na Tabela 1 .

Dentre os isômeros acima listados, o cis-9, trans-11, conhecido como ácido rumênico, é o que apresenta predominância em leite e derivados, constituindo mais de 90\% do conteúdo de CLA na gordura láctea (STANTON et al., 2003) e juntamente com o isômero trans-10, cis-12, são os mais estudados (NUNES; TORRES, 2010).

\section{Síntese de CLA}

O CLA pode encontrar-se naturalmente presente no leite e derivados lácteos, em 
decorrência do metabolismo dos ruminantes, assim como pode ser sintetizado por bactérias empregadas na elaboração dos derivados, sendo que esta última vem ganhando destaque.

A dieta dos animais ruminantes é composta basicamente por pastagem, que apresenta glicolipídios e fosfolipídios ricos em AL (18:2n-6) e $\alpha$-linolênico (18:3n-3), e ração produzida a partir de sementes oleaginosas, que contêm como ácidos graxos predominantes o linoleico e oléico (18:1n-9). Os lipídios ingeridos por esses animais passam por importantes transformações no rúmen, denominados de biohidrogenação (BUCCIONE et al., 2012), processo esse que ocorre a partir da ação de enzima bacteriana juntamente com a síntese endógena que ocorre no próprio tecido dos animais (Figura 1). Dentre as $10^{10}-10^{11}$ bactérias naturais do rúmen do gado, somente algumas espécies podem realizar as reações de biohidrogenação, com destaque a bactéria anaeróbia estrita Butyrivibrio fibrisolvens (SIEBER et al., 2004).

As etapas do processo de biohidrogenação do ácido linoleico estão representadas na Figura 1.

A isomerização da dupla ligação cis12 de ácidos graxos insaturados contendo duplas ligações nas posições cis-9, cis-12 (AL, $\alpha$ - e $\gamma$-linolênico) é o primeiro passo para a biohidrogenação destes compostos. A enzima responsável pela formação das duplas ligações conjugadas cis-9, trans-11 é

Tabela 1 - Isômeros posicionais e geométricos do ácido linoleico conjugado

\begin{tabular}{|c|c|c|c|}
\hline cis, trans & trans, cis & cis,cis & trans, trans \\
\hline cis-13, trans -15 & trans -12 , cis -14 & cis-12, cis-14 & trans -13 , trans -15 \\
\hline cis-12, trans-14 & trans-11,cis-13 & cis-11, cis-13 & trans -12, trans -14 \\
\hline cis-11, trans -13 & trans -10 , cis -12 & cis-10, cis-12 & trans -11, trans -13 \\
\hline cis -10, trans -12 & trans -9, cis -11 & cis-9, cis-11 & trans -10, trans -12 \\
\hline cis-9, trans-11 & trans -8 , cis -10 & cis-8, cis-10 & trans -9, trans -11 \\
\hline cis -8, trans -10 & trans -7 , cis -9 & cis -7, cis -9 & trans $-8, \operatorname{trans}-10$ \\
\hline cis -7, trans -9 & trans -6 , cis -8 & & Ttrans -7, trans -9 \\
\hline
\end{tabular}

Fonte: NUNES; TORRES (2010); SEHAT et al. (1998).

RUMEN (a)

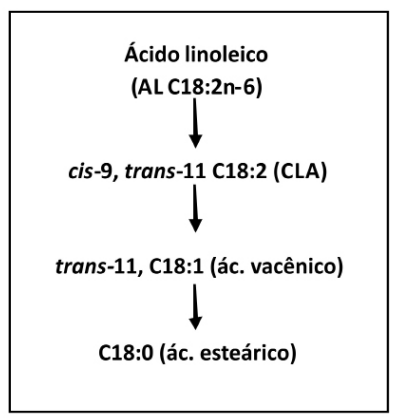

TECIDO (b)

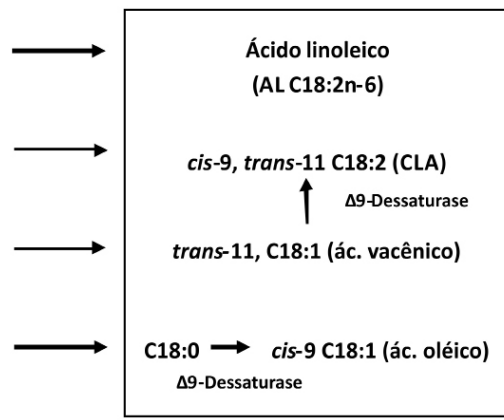

Figura 1 - a) Via metabólica de biossíntese do CLA no rúmen, b) Via metabólica de biossíntese do CLA no tecido. Fonte: Adaptado de Bauman; Griinari (2001) 
a linoleato isomerase. Em seguida, o isômero cis-9, trans-11 é reduzido ao ácido trans-11 octadicenóico, também denominado como ácido vacênico (BUCCIONE et al., 2012; WIJLEN; COLOMBANI, 2010). O ácido vacênico é o segundo intermediário da biohidrogenação do AL a ácido esteárico e é acumulado no rúmen, devido a sua menor taxa de conversão. Este composto é absorvido pelas glândulas mamárias e serve como substrato para a síntese endógena do isômero cis-9, trans-11 no tecido mamário, pela ação da enzima $\Delta 9$-dessaturase durante a síntese lipídica do leite. Segundo Sieber et al. (2004), estima-se que $78 \%$ de toda fração de cis-9, trans-11 presente no leite tenha origem na síntese endógena.

A conversão do AL ao isômero trans-10, cis-12 também é dependente da ação das bactérias naturais do rúmen e, segundo Buccione et al. (2012) está relacionada à presença do ácido trans-10 octadicenóico de forma análoga à formação de cis-9, trans-11 a partir do ácido trans-11 octadicenóico. Neste caso, entretanto, a enzima responsável pela síntese endógena é a $\Delta 12$-dessaturase.

A produção de CLA pelas bactérias do rúmen levou à especulação de que outros microrganismos também seriam capazes de sintetizar esse importante metabólito. Assim, estudos constataram a capacidade que algumas bactérias láticas têm em produzir CLA a partir de AL livre e que essa produção era cepa dependente (GORISSEN et al., 2010; RODRÍGUEZ-ALCALÁ et al., 2011). Dentre as bactérias láticas, destacam-se espécies de Bifidobacterium (GORISSEN et al., 2012), Proprionibacterium (WANG et al., 2007), Lactobacillus (LIN et al., 2005), sendo que algumas destas apresentam atividade probiótica e cujo um dos possíveis mecanismos de ação poderia estar correlacionado com a produção de CLA (O'SHEA et al., 2012).

O CLA produzido por algumas bactérias anaeróbias é um intermediário do processo de saturação de ácidos graxos poli-insaturados, já que estes ácidos livres podem inibir o crescimento dessas bactérias; por isso, as reações de saturação são supostos mecanismos de desintoxicação destes microrganismos. Deve-se, no entanto, observar os limites de tolerância de cada espécie, pois, apesar de atuar como principal substrato para a produção de CLA, a presença de altas concentrações de AL livre inibe completamente o crescimento de bactérias ácido láticas, resultando em baixa obtenção de CLA (OGAWA et al., 2005).

Apesar da produção de CLA ser dependente da cultura empregada, a adição de prebióticos (OLIVEIRA et al., 2009b) e fibras (ESPÍRITO SANTO et al., 2012), assim como a adição de AL livre (NIEUWENHOVE et al., 2007) podem também interferir positivamente na produção de CLA por bactérias ácido láticas.

\section{Variação do conteúdo de CLA no leite e derivados lácteos}

A existência de uma ampla faixa de variação nos níveis de CLA, em especial no leite, pode ser atribuída a fatores associados aos animais como espécie, raça, idade, estágio de lactação e também a fatores relacionados à dieta como incorporação de CLA, composição de ácidos graxos, variação sazonal e tipo de alimentação (TSIPLAKOU et al., 2006). Os leites de espécies ruminantes, como bovinos, caprinos, ovinos e bubalinos, são os que apresentam maior concentração de CLA, devido a capacidade desses animais de converter ácidos graxos insaturados em CLA (COLLOMB et al., 2006) (Tabela 2).

No leite, o conteúdo de CLA pode ser modificado pela manipulação da alimentação dos animais lactantes. Concentrações maiores de CLA foram observadas no leite de animais alimentados com pasto fresco, em detrimento daqueles alimentados com ração (TSIPLAKOU et al., 2008).

Maiores teores de CLA no leite também podem ser alcançados a partir da suplementação das rações com óleo ou sementes 
oleaginosas ricas em AL e $\alpha$-linolênico, como linhaça (GONTHIER et al., 2005), girassol (CASTRO et al., 2009), canola (COLLOMB et al., 2004) e soja (SECCHIARI et al., 2003) ou ainda de óleo de peixe (JONES et al., 2005).

Em relação aos derivados lácteos, a concentração de CLA é determinada pela concentração inicial deste no leite empregado como matéria-prima ou devido ao enriquecimento do produto.

Ledoux et al. (2005) obtiveram concentração média entre 0,45 a 0,80 g CLA/ $100 \mathrm{~g}$ de gordura láctea em manteiga produzida na França, observando maior concentração no verão.

Em relação ao teor de CLA em iogurte, o tipo de leite e a tecnologia de fabricação interferiram de forma significativa, sendo que os valores variam na faixa de $0,128 \mathrm{~g} / 100 \mathrm{~g}$ até $1,501 \mathrm{~g} / 100 \mathrm{~g}$ de gordura (Serafeimidou et al., 2013).

O teor de CLA em queijos pode variar de 0,05 a $2,86 \mathrm{~g} / 100 \mathrm{~g}$ de gordura, onde o tipo de leite, a alimentação e a origem geográfica afetam a concentração destes ácidos graxos (E1-SALAM; EL-SHIBIBY, 2014; PRANDINI et al., 2011). Quanto ao tipo de queijo, o período de maturação interfere nos teores de CLA, sendo maior para aqueles mais maturados, enquanto que o processo tecnológico (cozimento ou não da massa) e o teor de umidade não interferem significativamente (CICOGNINI et al., 2014).

Diante dos efeitos benéficos atribuídos ao CLA, uma das alternativas para se aumentar o teor deste em leite e derivados é a utilização de métodos de enriquecimento.

O queijo Edam e a manteiga elaborados a partir de leite de vaca enriquecido com CLA através da suplementação alimentar com óleo de canola apresentaram propriedades sensoriais aceitáveis, boas características de armazenamento e textura mais amolecida. $\mathrm{Na}$ manteiga, essa textura é vista como uma vantagem, enquanto, no queijo pode ser considerado um problema (RYHÄNEN et al., 2005).

Tecnologias como hidrólise enzimática por si (KONTKANEN et al., 2011), associada a transesterificação (SEHANPUTRI; HILL, 2003) ou empregando dióxido de carbono supercrítico (PRADO et al., 2012) contribuem para obtenção de gordura com maior teor de CLA.

A adição direta de CLA também vem sendo apontada como possível alternativa aos baixos conteúdos do ácido graxo poli-insaturado em alimentos (CAMPBELL et al., 2003). Por sua vez, o desenvolvimento de sabor e aroma indesejáveis, bem como a perda da qualidade nutricional nos alimentos enriquecidos com CLA, pode ocorrer devido a baixa estabilidade oxidativa de suas insaturações conjugadas.

Tabela 2 - Conteúdo CLA no leite de diferentes espécies

\begin{tabular}{ccc}
\hline Espécie & CLA (g.100 g- ${ }^{1}$ de lipídio) & \\
\hline Cabra & 0,68 & Ceballos et al. (2009) \\
& 0,45 & Ceballos et al. (2009) \\
\hline Vaca & 0,70 & Ménard et al. (2010) \\
& 0,65 & Dreiucker; Vetter (2011) \\
\hline Ovelha & 0,44 & Hilali et al. (2011) \\
\hline Búfala & 0,98 & Oliveira et al. (2009a) \\
& 0,90 & Ménard et al. (2010) \\
\hline Mulher & 0,42 & Dreiucker; Vetter (2011) \\
\hline
\end{tabular}


A microencapsulação do CLA antes da sua incorporação em alimentos pode ser considerada uma alternativa (LEE et al., 2009). Diante da dificuldade de incorporação direta do CLA em alimentos, a síntese deste composto a partir da ação de bactérias ácido lácticas pode representar uma alternativa à produção de alimentos enriquecidos com CLA, com características sensoriais agradáveis. A combinação de uma cultura produtora de CLA (Lactococcus lactis Cl4b) e de leite obtido a partir de vacas que receberam suplementação alimentar com óleo de peixe resultaram num queijo Cheddar com 2,6 vezes mais CLA do que o queijo elaborado sem a cultura láctica depois de seis meses (MOHAN et al., 2013).

\section{Propriedades funcionais}

Estima-se que a ingestão de cerca de 3 g.dia ${ }^{-1}$ seja necessária para que o CLA exerça seus efeitos benéficos (IP et al., 1991). No Brasil, entretanto, a ingestão média de CLA é estimada em 36 mg.dia ${ }^{-1}$ (NUNES; TORRES, 2010). Apesar do maior conteúdo de CLA observado nas dietas de países como Reino Unido (97,5 mg.dia-1) (MUSHTAQ et al., 2010); sua ingestão ainda é muito inferior à recomendada em todo o mundo.

A gama de propriedades funcionais atribuídas ao CLA deve-se à existência de um grande número de isômeros que, apesar da semelhança estrutural, possuem papéis biológicos distintos. Os efeitos relacionados à ingestão da grande maioria destes isômeros, bem como da interação entre eles, no entanto, ainda são desconhecidos, com exceção dos isômeros cis-9, trans-11 e trans-10, cis-12 (RAINER; HEISS, 2004). A atividade anticarcinogênica do CLA difere de acordo com o tipo de isômero. O isômero trans-10, cis-12, por exemplo, tem sido mais efetivo no combate ao crescimento celular associado ao câncer de colon in vitro do que o cis-9, trans-11 (PIERRE et al., 2013). Heinze;
Actis (2012) revisaram o efeito do CLA sobre o câncer de mama e Tanmahasamut et al. (2004) demonstraram que dentre os isômeros o cis-9, cis-11 pode apresentar propriedade antitumoral provavelmente por apresentar propriedade antiestrogênica em um estudo empregando células do câncer de mama.

Além da propriedade anticarcinogênica, outro aspecto que atrai a atenção dos pesquisadores é a capacidade do CLA de reduzir a fração lipídica corporal em animais, com destaque ao isômero trans-10, cis-12 (OBSEN et al., 2011). Vários mecanismos estão sendo propostos para explicar esta ação, entre eles, aumento do gasto energético, modulação do metabolismo dos adipócitos, modulação das adipocinas e citocinas e aumento da $\beta$-oxidação dos ácidos graxos (PARK; PARIZA, 2007). Devido a essa função catabólica, o CLA apresenta efeitos positivos sobre fatores de risco relacionados às doenças cardiovasculares, como redução do colesterol plasmático, dos níveis de triacilgliceróis e arterioesclerose (MOONEY et al., 2012).

Outras propriedades benéficas, como atividade anti-inflamatória (REYNOLDS; ROCHE, 2010) e promoção de melhorias no sistema imune (BASAGANYA-RIERA et al., 2012) tem sido apontadas e associadas com benefícios para aqueles que apresentam asma (MACREDMOND; DORSCHEID, 2011) e Alzeihmer (LEE et al., 2013). Porém, em relação ao papel do CLA sobre diabetes do tipo II, não há, ainda, um consenso geral entre os pesquisadores quanto ao efeito deste ácido graxo, sugerindo a necessidade de mais estudos (KOBA; YANAGITA, 2013).

A maioria das informações acerca das propriedades funcionais acima atribuídas ao CLA foram determinadas em sistemas modelo in vitro e em animais. Em relação aos estudos em humanos, menores em proporção, os resultados obtidos ou não são consistentes ou não similares quanto à eficácia comparado aos realizados em sistemas modelos, sugerindo a necessidade da realização de mais pesquisas 
para avaliar o real efeito do CLA na saúde humana (PARK, 2009; BATTACHARYA et al., 2006).

\section{Quantificação de CLA em produtos lácteos}

A estrutura química dos isômeros do CLA tem desafiado a análise de lipídios devido as suas propriedades físicas únicas e a possibilidade de formação de uma ampla gama de isômeros posicionais e geométricos (KRAMER et al., 2004). O reconhecimento dos diferentes papéis biológicos de cada um dos isômeros do CLA aumentou a importância do uso de métodos analíticos adequados, capazes de separar e quantificar os isômeros sem que ocorram isomerizações (CHRISTIE et al., 2007).

A análise dos ácidos graxos, bem como sua esterificação, só pode ser realizada após a extração dos lipídios da matriz do alimento (DOMAGALA et al., 2010). No caso do leite e seus derivados, no entanto, devem ser evitados métodos que envolvam etapas prévias de digestão, devido à possível isomerização do CLA, ou de solventes como hexano, éter de petróleo ou dietil éter, capazes de extrair apenas lipídios neutros (KRAMER; ZHOU, 2001). A extração de lipídios utilizando a mistura dos solventes orgânicos clorofórmio/ metanol/água nas proporções $8: 4: 3$, proposto por Folch (1957), ou 2:2:1.8, proposto por Bligh; Dyer (1959), tem apresentado resultados muito satisfatórios em leite e derivados (KRAMER; ZHOU, 2001).

Os padrões comerciais são, em geral, fornecidos na forma de ésteres metílicos ou ácidos graxos livres. Na gordura do leite, entretanto, os ácidos graxos encontram-se na forma de triacilgliceróis, o que exige um tratamento preliminar da amostra conhecido como esterificação, que consiste na conversão dos triacilgliceróis a ésteres metílicos de ácidos graxos, compostos menos polares e mais voláteis (FUENTE et al., 2006).
A grande variedade de ácidos graxos presentes no leite é um obstáculo para o preparo quantitativo dos ésteres metílicos. Os métodos mais comuns de esterificação são divididos em duas categorias: catálise ácida e catálise básica. As reações por catálise ácida apresentam bom desempenho na conversão de ácidos graxos livres e daqueles encontrados na forma de glicerídeos e fosfolipídios. No caso dos dienos conjugados, no entanto, a catálise ácida é responsável pela isomerização das ligações cis,trans à suas correspondentes trans,trans e/ou formação de derivados metoxi, o que faz dela um método inapropriado para esterificação do CLA (NUERNBERG et al., 2010).

A esterificação por catálise básica é um método rápido e pode ser realizado à temperatura ambiente, o que reduz o risco de decomposição dos ácidos graxos poliinsaturados e/ou isomerização das ligações cis, trans. Os reagentes mais utilizados nestas reações são soluções metanólicas de metóxidode sódio $\left(\mathrm{NaOCH}_{3}\right)$, hidróxido de potássio $(\mathrm{KOH})$ e hidróxido de sódio $(\mathrm{NaOH})$ (MILINSKI et al., 2011). Apesar de apresentar algumas desvantagens, como a incapacidade de esterificar ácidos graxos livres e outras frações lipídicas, como a esfingomielina, este método ainda é o mais indicados na análise quantitativa dos isômeros do CLA(KRAMER; ZHOU, 2001).

A análise dos isômeros do CLA sofreu intenso aprimoramento nos últimos anos através do uso de técnicas instrumentais, tais como, a cromatografia líquida de alta eficiência com íons de prata ( $\mathrm{AG}^{+}$-CLAE) (FUENTE et al., 2006); a espectroscopia de radiação infravermelha (CHRISTY, 2009), ressonância magnética nuclear (NMR) (PAJUNEN et al. 2008) e a cromatografia gasosa com detector de chama, utilizando colunas capilares longas $(100 \mathrm{~m})$ e de alta polaridade (SIMIONATO et al., 2010; KRAMER et al., 2004) ou combinada a técnicas complementares, como a 
espectroscopia de massa (MS) (ECKER et al., 2012).

\section{CONSIDERAÇÕES FINAIS}

Nos últimos anos, diversos componentes bioativos presentes no leite, em especial o CLA, têm atraído o interesse de pesquisadores. Devido aos inúmeros efeitos fisiológicos e considerando o baixo nível de ingestão diária, cientistas de todo mundo vêm desenvolvendo diferentes métodos de síntese e suplementação de CLA em diversos alimentos. Novos estudos são necessários, considerando que o conhecimento sobre os efeitos deste ácido graxo no organismo, bem como sobre as propriedades físico-químicas, sensoriais e reológicas nos alimentos ainda é limitado.

\section{REFERÊNCIAS}

ANDRADE, J. C. et al. Production of conjugated linoleic acid by food-grade bacteria: A review. International Journal of Dairy Technology, v. 65, n. 4, p. 467-481, 2012 .

BASAGANYA-RIERA, J. et al. Conjugated linoleic acid modulates immune responses in patients with mild to moderately active Crohn's disease. Clinical Nutrition, v. 31, n. 5, p. 721-727, 2012.

BATTACHARYA, A. et al. Biological effects of conjugated linoleic acids in health and disease. The Journal of Nutritional Biochemistry, v. 17, n. 12, p. 789-810, 2006.

BAUMAN, D. E.; GRIINARI, J. M. Regulation and nutritional manipulation of milk fat: low-fat milk syndrome. Livestock Production Science, v. 70, n.1-2, p. 15-29, 2001.

BLIGH, E. G.; DYER, W. J. A rapid method for total lipid extraction and purification. Canadian Journal of Biochemistry and Physiology, v. 37, n. 8, p. 911-917, 1959.

BUCCIONE, A. et al. Lipid metabolism in the rumen: New insights on lipolysis and biohydrogenation with an emphasis on the role of endogenous plant factors. Animal Feed Science and Technology, v. 174, n. 1, p. 1-25, 2012.

CAMPBELL, W.; DRAKE, M. A.; LARICK, D. K. The impact of fortification with conjugated linoleic acid (CLA) on the quality of fluid milk. American Dairy Science Association, v. 86, n. 1, p. 43-51, 2003.

CASTRO, T. et al. Effects of dietary sources of vegetable fats on performance of dairy ewes and conjugated linoleic acid (CLA) in milk. Small Ruminant Research, v. 84, n. 1-3, p. 47-53, 2009.

CEBAllos, L. S. et al. Composition of goat and cow milk produced under similar conditions and analyzed by identical methodology. Journal of Food Composition and Analysis, v. 22, n. 4, p. 322-329, 2009.

CHRISTIE, W. W. DOBSON; G.; ADLOF, R. $O$. A practical guide to the isolation, analysis and identification of conjugated linoleic acid. Lipids, v. 42, n. 12, p. 1073-1084, 2007.

CHRISTY, A. A. Evidence in the formation of conjugated linoleic acids from thermally induced 9t12t linoleic acid: a study by gas chromatography and infrared spectroscopy. Chemistry and Physics of Lipids, v. 161, n. 2, p. 86-94, 2009.

CICOGNINI, F. M. et al. Conjugated linoleic acid isomer (cis9, trans 11 and trans 10, cis 12) content in cheeses from Italian large-scale 
retail trade. International Dairy Journal, v. 34, n. 2, p. 180-183, 2014.

COLLOMB, M. et al. Impact of a basal diet of hay and fodder beet supplemented with rapeseed, linseed and sunflowerseed on the fatty acid composition of milk fat. International Dairy Journal, v. 14, n. 6, p. 549-559, 2004.

COLlOMB, M. et al. Conjugated linoleic acids in milk fat: Variation and physiological effects. International Dairy Journal, v. 16, n. 11, p. 1347-1361, 2006.

DOMAGALA, J. et al. The influence of cheese type and fat extraction method on the content of conjugated linoleic acid. Journal of Food Composition and Analysis, v. 23, n. 3, p. 238-243, 2010.

DREIUCKER, J.; VETTER, W. Fatty acids patterns in camel, moose, cow and human milk as determined with GC/MS after silver ion solid phase extraction. Food Chemistry, v. 126, n. 2, p. 762-771, 2011.

ECKER, J. et al. A rapid GC-MS method for quantification of positional and geometric isomers of fatty acid methyl esters. Journal of Chromatography B, v. 897, p. 98-104, may 2012.

EL-SALAM, M. H. A.; EL-SHIBINY, S. Conjugated linoleic acid and vaccenic acid contents in cheeses: An overview from the literature. Journal of Food Composition and Analysis, v. 33, n. 1, p. 117-126, 2014.

ESPÍRITO SANTO, A. P. et al. Fibers from fruit by-products enhance probiotic viability and fatty acid profile and increase CLA content in yoghurts. International Journal of Food Microbiology, v. 154, n. 3, p. 135144, 2012.
FOLCH, J.; LESS, M.; SLOANE STANLEY, G.H. A simple method for the isolation and purification of total lipids from animal tissues. The Journal of Biological Chemistry, v. 226, n. 1, p. 497-509, 1957.

FUENTE, M. A. de la; LUNA, P.; JUÁREZ, M. Chromatographic techniques to determine conjugated linoleic acid isomers. Trends in Analytical Chemistry, v. 25, n. 9, p. 917926, 2006.

GONTHIER, C. et al. Feeding micronized and extruded flaxseed to dairy caws: effects on blood parameters and milk fatty acid composition. Journal of Dairy Science, v. 88, n. 2, p. 748-756, 2005.

GORISSEN, L. et al. Production of conjugated linoleic acid and conjugated linoleic acid isomers by Bifidobacterium species. Applied Microbial and Cell Physiology, v. 87, n. 6, 2257-2266, 2010.

GORISSEN, L. et al. Conjugated linoleic and linolenic acid production kinetics by bifidobacteria differ among strains. International Journal of Food Microbiology, v. 155, n. 3, p. 234-240, 2012.

HEINZE, V. M.; ACTIS, A. B. Dietary conjugated linoleic acid and long-chain n-3 fatty acids in mamary câncer protection: a review. International Journal of Food Sciences and Nutrition, v. 63, n. 1, p. 6678, 2012.

H I L A L I, M . ; E L-M A Y D A , E .; RISCHKOWSKY, B. Characteristics and utilization of sheep and goat milk in the Middle East. Small Ruminat Research, v. 101, n. 1-3, p. 92-101, 2011.

IP, C. et al. Mammary Cancer Prevention by Conjugated Dienoic Derivative of Linoleic 
Acid. Cancer Research, v. 51, n. 22, p. $6118-$ 6124, 1991.

JONES, E. L. et al. Chemical, physical and sensory properties of dairy products enriched with conjugated linoleic acid. Journal of Dairy Science, v. 88, n. 8, p. 2923-2937, 2005.

KOBA, K.; YANAGITA, T. Health benefits of conjugated linoleic acid (CLA). Obesity Research \& Clinical Practice, In Press, 2013. Disponível em: <http:// www.sciencedirect.com/science/article/pii/ S1871403X13001968>. Acesso em: 18 nov. 2013.

KONTKANEN, H. et al. Enzymatic and physical modification of milk fat: a review. International Dairy Journal, v. 21, n. 1, p. 3-13, 2011.

KRAMER, J. K. G.; ZHOU, J. Conjugated linoleic acid and octadecenoic acids: Extraction and isolation of lipids. European Journal of Lipid Science and Technology, v. 103, n. 9, p. 594-632, 2001.

KRAMER, J. K. G. et al. Analysis of conjugated linoleic acid and trans 18:1 isomers in synthetic and animal products. American Journal of Clinical Nutrition, v. 79, 6 suppl., p. 1137S1145S, 2004.

LEDOUX, M. et al. Fatty acid composition of french butters, with special emphasis on conjugated linoleic acid (CLA) isomers. Journal of Food Composition and Analysis, v. 18 , n. 5, p. 409-425, 2005.

LEDOUX, M.; JUANÉDA, P.; SÉBÉDIO, J. L. Trans fatty acids: Definition and occurrence in foods. European Journal of Lipid Science and Technology, v. 109, n. 9, p. 891-900, 2007.
LEE, E. et al. Effect of conjugated linoleic acid, $\mu$-calpain inhibitor, on pathogenesis of Alzheimer's disease. Biochimica et Biophysica Acta, v. 1831, n. 4, p. 709-718, 2013.

LEE, J. et al. Optimization and oxidative stability of the microencapsulated conjugated linoleic acid. International Journal of Biological Macromolecules, v. 45, n. 4, p. 348-351, 2009.

LIN, T. Y.; HUNG, T. H.; CHENG, T. S. J.. Conjugated linoleic acidproduction by immobilized cells of Lactobacillus delbrueckii ssp. bulgaricus and Lactobacillus acidophilus. Food Chemistry, v. 92, n. 1, p. 23-28, 2005.

MACREDMOND, R. R.; DORSCHEID, D. R. Conjugated linoleic acid (CLA): Is it time to supplement asthma therapy? Pulmonary Pharmacology \& Therapeutics, v. 24, n. 5, p. 540-548, 2011.

MARTIN, C. A. et al. Trans fatty acidforming processes in foods: a review. Anais da Academia Brasileira de Ciências. v. 79, n. 2, p. 343-350, 2007.

MÉNARD, O. et al. Buffalo vs. cow milk fat globules: size distribution, zeta-potential, composition in total fatty acids and in polar lipids from the milk fat globule membrane. Food Chemistry, v. 120, n. 2, p. 544-551, 2010.

MILINSKI, M. C. et al. Influência do método de esterificação na quantificação de ácidos graxos em óleo de oliva. Semina: Ciências Exatas e Tecnológicas, v. 32, n. 2, p. 139$150,2011$.

MOHAN, M. S. et al. Starter cultures and cattle feed manipulation enhance conjugated 
linoleic acid concentrations in Cheddar cheese. Journal of Dairy Science, v. 96, n. 4, p. 2081-2094, 2013.

MOONEY, D.; McCARTHY, C.; BELTON, $\mathrm{O}$. Effects of conjugated linoleic acid isomers on monocyte, macrophage and foam cell phenotype in atherosclerosis. Prostaglandins \& Other Lipid Mediators, v. 98, n. 3-4, p. 56-62, 2012.

MOTARD-BÉLANGER, A. et al. Study of the effect of trans fatty acids from ruminants on blood lipids and other risk factor for cardiovascular disease. The American Journal of Clinical Nutrition, v. 87, n. 3, p. 593-599, 2008.

MOZAFFARIAN, D. et al. Trans fatty acids and cardiovascular disease. The New England Journal of Medicine, v. 354, n. 15, p. 1601-1613, 2006.

MUSHTAQ, S.; HEATHER MANGIAPANE, E.; HUNTER, K. A. Estimation of cis9, trans-11 conjugated linoleic acid content in UK foods and assessment of dietary intake in a cohort of healthy adults. British Journal of Nutrition, v. 103, n. 9, p. 13661374, 2010.

NIEUWENHOVE, C. P. V. et al. Influence of bacteria used as adjunct culture and sunflower oil addition on conjugated linoleic acid content in buffalo cheese. Food Research International, v. 40, n. 5, p. 559-564, 2007.

NUERNBERG, $\mathrm{k}$. et al. Comparison of different methylation methods for the analysis of conjugated linoleic acid isomers by silver ion HPLC in beef lipids. Journal of Agricultural and Food Chemistry, v. 55, n. 5, p. 598-602, 2007.

NUNES, J. C.; TORRES, A. G. Fatty acid and
CLA composition of Brazilian dairy products, and contribution to daily intake of CLA. Journal of Food Composition and Analysis, v. 23, n. 8, p. 782-789, 2010.

OBSEN, T. et al. Trans-10, cis-12, conjugated linoleic acid decreases de novo lipid synthesis in human adipocytes. Journal of Nutricional Biochemestry, v. 23, n. 6, p. 580-590, 2011.

OGAWA, J. et al. Production of conjugated fatty acids by lactic acid bacteria journal of bioscience and bioengineering. The Society for Biotechnology, v. 100, n. 4, p. 355-364, 2005.

OLIVEIRA, R. et al. Effects of dietary fat sources on intake, nutrient digestibility and plasma urea nitrogen for lactating water buffaloes. Revista Brasileira de Zootecnia, v. 38 , n. 3, p. 553-559, 2009a.

OLIVEIRA, R. P. S. et al. Effect of different prebiotics on the fermentation kinetics, probiotic survival and fatty acids profiles in nonfat symbiotic fermented milk. International Journal of Food Microbiology, v. 128, n. 3, p. 467-472, 2009 b.

O'SHEA, E. F. et al. Production of bioactive substances by intestinal bacteria as a basis for explaining probiotic mechanisms: bacteriocins and conjugated linoleic acid. International Journal of Food Microbiology, v. 152, n. 3, p. $189-205,2012$.

PAJUNEN, T. I. et al. NMR properties of conjugated linoleic acid (CLA) methyl ester hydroperoxides. Chemistry and Physics of Lipids, v. 154, n. 2, p. 105-114, 2008.

PARK, Y. Conjugated linoleic acid (CLA): Good or bad trans fat? Journal of Food Composition and Analysis, v. 2, suppl., p. S4-S12, 2009. 
PARK, Y.; PARIZA, M. Mechanisms of body fat modulation by conjugated linoleic acid (CLA). Food Research International, v. 40, n. 3, p. 311-323, 2007.

PIERRE, A. S. et al. Trans-10, cis12 conjugated linoleic acid induced cell death in human colon cancer cells through reactive oxygen species-mediated ER stress. Biochimica et Biophysica Acta, v. 183, n. 4, p. 759-768, 2013.

PRADO, G. H. C. et al. Enzymatic hydrolysis of conjugated linoleic acid-enriched anhydrous milk fat in supercritical carbon dioxide. The Journal of Supercritical Fluids, v. 66, p. 198-206, jun. 2012.

PRANDINI, A.; SIGOLO, S.; PIVA, G. A comparative study of fatty acid composition and CLA concentration in commercial cheeses. Journal of Food Composition and Analysis, v. 24, n. 1, p. 55-61, 2011.

RAINER, L.; HEISS, C. J. Conjugated linoleic acid: health implications and effects on body composition. Journal of the American Dietetic Association, v. 104, n. 6, p. 963968, 2004.

REYNOLDS, C. M.; ROCHE, H. M. Conjugated linoleic acid and inflammatory cell signalling. Prostaglandins, Leukotrienes and Essential Fatty Acids, v. 82, n. 4-6, p. 199-204, 2010.

RODRÍGUEZ-ALCALÁ, L. M. et al. Quantitative and qualitative determination of CLA produced by Bifidobacterium and lactic acid bacteria by combining spectrophotometric and Ag+-HPLC techniques. Food Chemistry, v. 125, n. 4, p. 1373-1378, 2011.

RYHÄNEN, E. L. et al. Production of conjugated linoleic acid enriched milk and dairy products from cows receiving grass silage supplemented with a cerealbased concentrate containing rapeseed oil. International Dairy Journal, v. 15, n. 3, p. 207-217, 2005.

SECCHIARI, P. et al. Effect of kind of dietary fat on the quality of milk fat from Italian Friesian cows. Livestock Production Science, v. 83, n. 1, p. 43-52, 2003.

SEHANPUTRI, P.; HILL, C. Lipase-mediated acidolysis of butteroil with free conjugated linoleic acid in a packed bed reactor. Biotechnology and Bioengineering, v. 83, n. 5 , p. 608-617, 2003.

SEHAT, N. et al. Identification of conjugated linoleic acid isomers in cheese by gas chromatography, silver ion high performance liquid chromatography and mass spectral reconstructed ion profiles. Comparison of chromatographic elution sequences. Lipids, v. 33, n. 10, p. 963-971, 1998.

SERAFEIMIDOU, A. et al. Change of fatty acid profile, including conjugated linoleic acid (CLA) content, during refrigerated of yogurt made of cow and sheep milk. Journal of Food Composition and Analysis, v. 31, n. 1, p. 24-30, 2013.

SIEBER, R. et al. Impact of microbial cultures on conjugated linoleic acid in dairy products. International Dairy Journal, v. 14, n. 1, p. 1-15, 2004.

SIMIONATO, J. I. et al. Validation of the determination of fatty acids in milk by gas chromatography. Journal of Brazilian Chemical Society, v. 21, n. 3, p. 520-524, 2010 .

STANTON, C. et al. Animal feeding strategies for conjugated linoleic acid enrichment of 
milk. IN: SEBÉDIO, J. L. et al. Advances in Conjugated Linoleic Acid Research. Champaign:AOCS Press, 2003. v. 2, 123$145 \mathrm{p}$.

TANMAHASAMUT, P. et al. Conjugated linoleic acid blocks estrogen signaling in human breast cancer cells. American Society for Nutritional Sciences, v. 22, n. 3, p. 31603166, 2004.

TSIPLAKOU, E.; KOMINAKIS, A.; ZERVASA, G. The interaction between breed and diet on CLA and fatty acids content of milk fat of four sheep breeds kept indoors or at grass. Small Ruminant Research, v. 74, n. 1-3, p. 179-187, 2008.
TSIPLAKOU, E. MOUNTZOURIS, K. C.; ZERVAS, G. Concentration of conjugated linoleic acid in grazing sheep and goat milk fat. Livestock Science, v. 103, n. 1-2, p. 7484, 2006.

WANG, L. M. et al. Production of conjugated linoleic acid by Propionibacterium freudenreichii. Food Chemistry, v. 103, n. 2, p. 313-318, 2007.

WiJlen, R. P. J.; COLOMBANI, P. C. Grass-based ruminant production methods and human bioconversion of vaccenic acid with estimations of maximal dietary intake of conjugated linoleic acids. International Dairy Journal, v. 20, n. 7, p. 433-448, 2010. 